\title{
TYPE A BEHAVIOR, WORK OUTCOMES AND PSYCHOLOGICAL WELL-BEING: ACHIEVEMENT STRIVING VERSUS IMPATIENCE ${ }^{1}$
}

\author{
RONALD J. BURKE \\ York University \\ ASTRID RICHARDSEN \\ Norwegian School of Management \\ MONICA MARTINUSSEN \\ University of Tromso
}

\begin{abstract}
This study investigated the effects of two Type A Behavior Pattern (TABP) dimensions on job and life satisfaction and psychosomatic symptoms: Achievement Striving (AS) and Impatience-Irritability (II), in a large sample of Norwegian human service workers $(N=1590)$. The effects of three job demands (work conflict, work-family conflict, lack of autonomy) were also considered. Data were collected using questionnaires. AS and II were uncorrelated as predicted and had different patterns of relationship with job stressors and the satisfaction and well-being outcomes; II had a negative relationship with job and life satisfaction and a positive relationship with psychosomatic symptoms while AS had a positive relationship with life satisfaction. AS and II contributed additional explained variance on all dependent variables controlling for personal and work situation characteristics. Few TABP dimension $X$ job demands interactions were significant suggesting that $A S$ and II likely influence outcomes directly rather than in interaction with job demands.
\end{abstract}

Keywords: Psychological well-Being, Behavior, Work Outcomes

Type A Behavior, Work Outcomes and Psychological Well-Being: Achievement Striving Versus Impatience

${ }^{1}$ Preparation of this manuscript was supported in part by the Schulich School of Business, York University, the Norwegian Institute of Management, the Department of Psychology, University of Tromso, the Norwegian Research Council and the Psychiatric Research Center for the counties Finnmark and Tromso. We thank our respondents for their cooperation. Lisa Fiksenbaum assisted with data analysis. 
Friedman and Rosenman (1974), based on observations of patients with coronary heart disease (CHD), proposed that $\mathrm{CHD}$ was associated with a behavior pattern they labeled Type $A$. The Type A Behavior Pattern (TABP) was initially characterized by competitiveness, ambitiousness, impatience, time urgency, aggressiveness and hostility; Individuals low in these characteristics were labelled Type B. TABP was defined as an action-emotion complex stimulated by certain environmental events.

Several studies have reported a relationship of TABP with the incidence of CHD (Rosenman, Friedman, Straus, et al, 1964; Rosenman, Brand, Jenkins, Friedman, Straus \& Wurm, 1975; Yoshimasu, 2001; Haynes, Levine, Scotch, Feinleib \& Kannel, 1978; Rosenman, Brand, Sholts \& Friedman, 1976; French Belgian Collaborative Group, 1982; Haynes, Feinleib \& Kannel, 1980; Kayaba, Yazawa, Natsume, Yaginuma, Hasaka, Hosoda \& Tanada, 1990) Others however, have indicated conflicting results (e.g., Booth-Kewley \& Friedman, 1987; Shekelle, Holley, Neaton, Billings, Bozhani, Gerace, Jacobs, Lasser, Mittlemark \& Stamler, 1985; Pickering, 1985). Efforts were then made to more clearly determine what the TABP scales were actually measuring and those aspects of TABP that might be particularly lethal (Edwards, Baglioni \& Cooper, 1990; Friedman \& Booth-Kewley; 1987 Mathews \& Haynes, 1986; Shekelle, Gale \& Norusis, 1985).

Since that time, a number of researchers have identified specific components within the early TABP constellation that were particularly critical in the incidence of CHD. Thus, anger, hostility and aggression emerged as important TABP elements in the development of CHD (Mathews, 1982; Rosenman, 1985; Siegman \& Smith, 1994).

Several of the TABP components proposed by Friedman and Rosenman encompass achievement-oriented motivations and behaviors such as ambition, competitiveness and time urgency. These TABP components have been found to be associated with superior academic and performance (Spence, Heinreich \& Pred, 1987). It seemed unlikely that the same TABP components would be related to both stronger academic and professional performance and to $\mathrm{CHD}$ and other health problems. That is, different components of TABP were more likely to be related to performance and to health problems (see Barling \& Charbonneau, 1992).

Analyses of the measures most frequently used to assess TABP bear this out. For example, Pred, Helmreich and Spence (1987) report the results of factor analyses of the Jenkins Activity survey (JAS), the most widely used paper-and-pencil assessment of TABP (Jenkins, 
Zysanski \& Rosenman, 1979). They identified two factors: Achievement Striving (AS) and Impatience-Irritability (II). In a study of university students, they found that AS and II were relatively independent, that AS was associated with academic grade point average but not physical complaints, while II was associated with physical complaints but not grade point average. These findings suggest that considering the two components separately has merit (Spence, Helmreich \& Pred, 1987; Spence, Pred \& Helmreich, 1989).

Hansson, Hogan and Johnson (1983) also viewed the JAS as containing a heterogenous mixture of items that addressed constructive career involvement and self-defeating interpersonal behaviors. They developed two TABP measures; Drivenness (anxiety-related items) and Involvement (ambition-related items). These measures were then correlated with other psychological constructs in a sample of 69 male undergraduates. Drivenness was positively related to anxiety, negatively related to interpersonal perceptiveness and unrelated to ambition. Involvement was positively related to ambition and to interpersonal competence but unrelated to anxiety.

Friedman and Rosenman (1974) noted that TABP was also associated with marital dissatisfaction. Burke and his colleagues (Burke, Weir \& DuWors, 1979; 1980; Burke \& Weir, 1980) provided further empirical support for these observations using an overall measure of TABP developed by Bortner and Rosenman (1967). Barling, Bluen and Moss (2001) assessed AS and II separately in a sample of 134 medical practitioners and their wives in South Africa. Husbands' II was associated with their own and their wives' marital dissatisfaction; AS was uncorrelated with their own and their wives' marital dissatisfaction.

In addition to whatever role of TABP plays in CHD, it appears to be an interpersonal style related to psychological functioning (Ivancevich \& Matteson, 1988). An increasing number of researchers have explored TABP in the workplace (Chesney \& Rosenman, 1980; Helmreich, Spence \& Pred, 1988; Schnall \& Landsbergis, 1999; Hagihara, Tarumi \& Marimoto, 1998; Chesney, Sevelius, Black, Word, Swan \& Rosenman, 1981; Iwata, Suzuki, Saito \& Abe, 1992).

For example, Bluen, Barling and Burns (1990), in a study of 117 life insurance salespersons, examined the relationship of AS and II and job performance (number of policies sold), work attitudes (job satisfaction) and depression. After controlling for demographic characteristics and II, AS predicted number of policies sold and job satisfaction but not depression. And after controlling for demographics 
and AS, II was associated with higher levels of depression, less job satisfaction but not with number of policies sold.

In a later study, Day and Jreige (2002) considered AS and II as predictors of job stressors, job and life satisfaction and perceived stress. They found no correlation between AS and II; they were independent TABP components. Second, after controlling for both age and four job stressors, both AS and II accounted for additional variance in job and life satisfaction and perceived stress; AS contributed positively to job satisfaction, while II contributed negatively to life satisfaction and positively to perceived stress. Third, AS and II moderated some of the stressor-satisfaction and stressor outcome relationships. II and AS moderated the relationship between particular stressors and outcomes but in opposite directions; II exacerbated these relationships while AS tempered them.

Hallberg, Johannson and Schaufeli (2006), in a study of 329 information technology consultants, examined the relationship of AS and II measured by an adjective checklist developed by Blumenthal, Herman, O'Toole, Haney, Williams and Barefoot (1985) and work engagement and burnout, as well as considering the role of job factors such as job stressors (e.g., workload, reciprocity) and resources (e.g., autonomy) and the interaction of AS and II with these job factors. They found that AS and II were significantly positively correlated $(r=.30, p<$ .001). AS was also positively correlated with work enjoyment and negatively correlated with burnout while II was positively correlated with burnout and negatively correlated with work enjoyment. Some of the interaction terms between the two TABP components and the three job factors were significant leading the researchers to advocate that future research examine the effects of TABP components on outcomes through job demands rather than in interaction with job demands. Thus, while TABP may have fallen out of favor in research on CHD, it may serve as a useful individual difference variable in organizational behavior research. It is vital, however, that TABP components be considered separately.

The present study replicates the Day and Jreige (2002), Bluen, Barling and Burns (1990) and Hallberg, Johansson and Schaufeli (2006) investigations using the same measures of AS and II but different job demands and work and well-being outcomes in a different sample. Five hypotheses were considered.

1. AS and II would be uncorrelated with each other. 
2. AS and II would show different patterns of relationships with job demands, satisfaction and well-being outcomes.

3. AS and II would account for additional variance in work and well-being outcomes controlling for personal demographics, work situation characteristics and job demands.

4. AS would moderate the relationship between the job demands and the work and well-being outcomes such that high AS would reduce the negative outcomes of the job demands.

5. II would moderate the relationship between the job dmeands and the work and well-being outcomes such that high II would exacerbate the negative outcomes of the job demands.

Method

Procedure

Data were collected using questionnaires. A random sample of participants from four national professional unions were invited to participate along with nurses and nurses' aids from the local university hospital and a random sample of teachers from the Oslo School District. The questionnaires were sent to 3919 participants and a total of 1677 questionnaires were returned, representing a response rate of $43 \%$. Questionnaires with missing data in excess of $25 \%$ were excluded leaving a final data set of 1590 questionnaires. The participants consisted of seven different professions (see Table 1). About $81 \%$ were females with teachers comprising the largest occupational group (26\%).

\section{Enter Table 1 About Here}

\section{Respondents}

Table 2 presents the demographic characteristics of the sample. The majority were female $(80 \%)$, married $(72 \%)$, most had no children living at home $(53 \%)$, most worked full-time $(72 \%)$, most had five or fewer years of job and organizational tenure $(72 \%$ and $54 \%$ respectively), a majority were between 31-50 years of age (55\%), most were in non-managerial jobs $(68 \%)$, most worked in units of 20 or fewer people $(44 \%)$, most worked $36-50$ hours per week $(52 \%)$, most worked 50 or fewer hours of overtime per month (54\%), and the majority earned between 200,000 - 299,000 Norwegian Krona per year.

\section{Enter Table 2 About Here}


Measures

\section{Personal demographics}

A number of personal demographic characteristics were measured by single items: age, level of education, marital status, children living at home, full or part-time work status and gender.

Work situation characteristics

A variety of work situation characteristics were also measured by single items: organizational size, job tenure, organizational tenure, and organizational level.

\section{TABP behavior}

Two aspects of TABP behavior, Achivement Striving (AS) and Impatience-Irritation (II) were assessed using the Revised Jenkins Activity Survey (Pred, Helmreich \& Spence, 1987; Spence, Helmreich \& Pred, 1987). Both scales consisted of six items. Respondents indicated the alternative that best described them or their opinion on a five-point Likert scale. An item on the AS scale was "How seriously do you take your work", an item on the II scale was "Do you usually get irritated".

Job Demands

Three job demands were included each measured by multiple items.

Work Conflict

Work conflict was measured by two items $(\alpha=.72)$ : "I often experience conflict with other colleagues at work" and "I often experience conflict with my superiors at work". Respondents indicated their agreement with each on a five-point Likert scale ( 1 = strongly disagree, 3 = uncertain, 5 = strongly agree).

Work-family conflict was also measured by two items $(\alpha=.70)$. One item was "I often feel conflict between my work and my family or other personal commitments".

Lack of Autonomy was measured by two items $(\alpha=.66)$. One item was "to what extent are you able to influence your workload?"

\section{Job Satisfaction}

This was measured by a five item scale $(\alpha=.84)$ developed by Quinn and Shepard (1974). One item was "All is well, how satisfied would you say you are with your job?" 
Life satisfaction: This three-item scale $(\alpha=.90)$ was taken from Caplan, Cobb, French, Harrison and Pinneau (1975). A sample item was "I am very satisfied with my life."

Psychosomatic symptoms: This 20-item scale $(\alpha=.84)$ was developed be Derogatis, Lipman, Rickels, Uhlenhuth and Covi (1979). Sample items included headaches and having trouble getting to sleep.

Results

Analysis Plan

Hierarchical regression analyses were undertaken with predictor variables entered in a specified order. The first block were the personal demographic variables $(\mathrm{N}=)$. The second block were the work situation characteristics $(N=)$. The third block were the job demands $(\mathrm{N}=3)$. The fourth block were the two TABP measures (AS and II). The fifth and final block were the interactions between the two TABP behaviors and the three work stressors. The first two blocks served as control variables before considering the effects of TABP behaviors, job demands, and their interactions on the three work and well-being outcomes. When a block of predictors accounted for a significant amount on increment in explained variance or a given outcome measure $(p<.05)$, all variables within these blocks having independent and significant relationships with this outcome were identified $(p<.05)$. Table 3 shows the results of these hierarchical regression analyses.

Enter Table 3 About Here

\section{Job Satisfaction}

Three blocks of predictors accounted for a significant amount or increment in explained variance on job satisfaction: personal demographics, job demands and TABP. Respondents working full-time were more job satisfied $(\beta=.08)$; respondents without children were more job satisfied $(\beta=-.06)$; respondents indicating less work conflict, less work-family conflict and more autonomy were more job satisfied ( $\beta_{\mathrm{s}}$ $=-.20,-.19$ and -.15 , respectively); respondents scoring lower on II and higher on AS were also more job satisfied $\left(\beta_{\mathrm{s}}=-.22\right.$ and .12 respectively). The interaction term was not significant.

\section{Life Satisfaction}

Four blocks of predictors accounted for a significant amount or increase in explained variance on life satisfaction: personal demographics, work situation characteristics, job demands and TABP 
behaviors. Married respondents indicated more life satisfaction $(\beta=$ $.18)$, younger respondents indicated more life satisfaction $(\beta=-.12)$; respondents working full time were more life satisfied $(\beta=-.06)$; respondents reporting less work conflict and less work-family conflict were more satisfied with their lives $\left(\beta_{\mathrm{s}}=-.14\right.$ and -.08 , respectively) and respondents scoring lower on II and respondents scoring higher on AS were more satisfied with their lives $\left(\beta_{s}=-.38\right.$ and .07 respectively). Once again the block of interaction terms did not explain a significant increment in explained variance on life satisfaction.

\section{Psychosomatic Symptoms}

Four blocks of predictors accounted for a significant amount or increment in explained variance on psychosomatic symptoms; personal demographics, job demands, TABP behavior and job demands X TABP interactions. Respondents working part-time reported more psychosomatic symptoms $(\beta=.13)$; older respondents reported more psychosomatic symptoms $(\beta-.11)$; less educated respondents reported more psychosomatic symptoms $(\beta=-.08)$ and respondents with children reported more psychosomatic symptoms $(\beta=-.07)$; respondents reporting higher levels of work-family conflict, lack of autonomy, and work conflict also reported more psychosomatic symptoms $\left(\beta_{\mathrm{s}}=.28\right.$, .14 and .05, respectively); respondents scoring higher on 11 also indicated more psychosomatic symptoms $(\beta=.25)$ and the autonomy $X$ AS interaction $(B=-.49)$ and the autonomy of $A S$ interaction $(B=.26)$ were statistically significant.

Although the interaction term reached statistical significance in only one analysis, Evans (1985) has suggested that an examination of the interaction terms is warranted if it accounts for more than $1 \%$ of the variance. This resulted in the following significant interaction of effects.

Job satisfaction

Work conflict X TABP (11)

Life satisfaction

Work conflict X TABP (11)

Psychosomatic symptoms

Autonomy $X$ TABP (11 and AS)

In each case, high II had a negative impact on these three outcomes. Respondents high on II indicated less job satisfaction than respondents low on II when work conflict was low but even lower job satisfaction when work conflict was high (a larger gap). 
Respondents high on II indicated less life satisfaction than respondents had on II when work conflict was low but even lower life satisfaction when work conflict was high (a larger gap). Respondents high on II indicated more psychosomatic complaints than respondents low on II when lack of autonomy was low but indicated even more psychosomatic complaints when lack of autonomy was high (a larger gap). Finally, respondents higher on AS indicated more psychosomatic complaints than respondents low on AS when lack of autonomy was high and fewer psychosomatic complaints when lack of autonomy was low.

\section{Discussion}

The findings shown in Table 3 replicate previous conclusions. First, respondents reporting higher levels of job demands were less satisfied with their jobs and lives and reported more psychosomatic symptoms. Second, II was associated with lower satisfaction and greater distress whereas AS was associated with greater satisfaction.

The following specific results were obtained. First, AS and II were only weakly correlated supporting our first hypothesis. Second, AS was generally positively correlated with work and well-being outcomes while II was generally negatively correlated with these outcomes supporting our second hypothesis. Third, AS and II contributed significant increments in explained variance on work and well-being outcomes, controlling for personal demographics, work situation characteristics and job demands, supporting our third hypothesis. Fourth, interactions between AS and II and the three job demands contributed significant increments in explained variance in some analyses providing partial support for our fourth and fifth hypotheses.

Thus, II generally maintained negative relationships with work and well-being outcomes, while AS maintained generally positive relationships with these outcomes, controlling for other variables. As an example of some significant interactions, consider these two specific interactions. In the interaction of AS and work-family conflict on psychosomatic complaints, high AS individuals indicated more psychosomatic complaints when work family conflict was low but indicated fewer psychosomatic complaints when wok family conflict was high. In addition, while high II individuals reported less job satisfaction than low II individuals when work conflict was either low or high, the difference between the high and low II groups was larger under high work conflict. 
The results of the present study confirm previous findings and extend our understanding of job demands and strain. First, AS and II were found to be independent factors in TABP. Second, AS and II exhibited different patterns of relationships with job demands and psychosocial outcomes. II was generally associated with greater job stressors and less positive well-being outcomes; AS was associated with lower job stressors and more positive well-being outcomes. These results were maintained when personal demographics and work situation characteristics were controlled. Finally, there was partial support for the moderating impact of both AS and II on the relationship between job demands and psychosocial outcomes.

There was only partial support for the moderating impact of AS and II on the relationship between job demands and work and wellbeing outcomes. Although only one of three blocks of interactions was significant, all three blocks of interactions were considered and four interactions were significant. Three of these interactions involved II. II seemed to exacerbate the relationship of work conflict on both job satisfaction and life satisfaction and lack of autonomy on psychosomatic symptoms. High AS seemed to moderate the effects of lack of autonomy on psychosomatic symptoms.

Kivimaki, Kalimo and Julkinen (1996) failed to find significant stressor X Type A interactions in their study. Although such interactions were present in the present study, and that undertaken by Day and Jreige (2002), further research is needed to determine the generalizability of these latter findings.

This research suggests that TABP is a useful individual difference variable relevant to the experience of working and the way work impacts satisfaction and well-being. AS and II were found to help or hinder ways individuals handled job demands. While reducing job demands in organizations is likely to be helpful, it may not be sufficient. It is important to consider and understand the role that individual perceptions and behaviors play in the work environment/well-being transaction.

The results of this study hold important implications for further research and theorizing on the relationship between TABP and behavior in organizations. Interventions to alleviate the negative effects of TABP could focus on reducing II and encouraging AS, since research has shown that II is consistently associated with various negative effects whereas AS is not, and in fact predicts positive work performance (e.g., Barling \& Charbonneau, 1988; Helmreich et al., 1988; Spence et al., 1987). 


\section{Limitations of the Research}

Some limitations of the study should be noted to put the results in a broader context. First, although the sample size was relatively large, the response rate, though typical of studies of this kind, was only $43 \%$. Second, all data were collected using self-report questionnaires raising the possibility of common method variance and response set tendencies. Third, it is not clear the extent to which these findings generalize to non-human service occupations or to occupations in other countries. 


\section{References}

Barling, J., \& Charbonneau, D. (1992) Disentangling the relationship between the achievement striving and impatience-irritability dimensions of type A behavior, performance and health. Journal of Organizational Behavior, 13, 369-377.

Barling, J., Bluen, S. \& Moss, V. (2001) Type A behavior and marital dissatisfaction: Disentangling the effects of Achivement Striving and Impatience-Irritability. Journal of Psychology, 124, 311-319.

Bluen, S.D., Barling, J. \& Burns, W. (1990) Predicting sales performance, job satisfaction, and depression by using the achievement strivings and impatience-irritability dimensions of Type A behavior, Journal of Applied Psychology, 75, 212-216.

Blumenthal, J.A., Herman, S., O'Toole, L., Haney, T.L., Williams, R., \& Barefoot, J. (1985). Development of a brief self-report measure of the Type-A (coronary prone) behavior pattern. Journal of Psychosomatic Research, 29, 265-275.

Booth-Kewley, S., \& Friedman, H.S. (1987) Psychological predictors of heart disease: A quantitative review. Psychological Bulletin, 101, 343-362.

Bortner, R.W., \& Rosenman, R.H. (1967) The measurement of Pattern A behavior. Journal of Chronic Disorders; 20: 525-33.

Burke, R.J. \& Weir, T. (1980) The Type A experience: Occupational and life demands, satisfaction and well-being. Journal of Human Stress, 6 , 28-38.

Burke, R.J., Weir, T. \& DuWors, R.E. (1979) Type A behavior of Administrators' and wives' reports of marital satisfaction and well-being Journal of Applied Psychology, 64, 57-65.

Burke, R.J., Weir, T. \& DuWors, R.E. (1980) Perceived Type A behavior of husbands' and wives' satisfaction and well-being Journal of Occupational Behavior, 1, 139-150.

Caplan, R.D., Cobb, S., French, J.R.P., Harrison, R.V. and Pinneau, S.R., (1975) Job Demands and Worker Health, NIOSH Research Report, US Government Printing Office, Washington, DC.

Chesney, M.A., \& Rosenman, R.H. (1980) Type A behavior in the work setting. In C.L. Cooper \& R. Payne (Eds.) Current Concerns in Occupational Stress. London: Wiley, 187-212. 
Chesney, M.A., Sevelius, G., Black, G.W., Ward, M.M., Swan, G.E., \& Rosenman, R.H., (1981) Work environment, type A behavior and coronary heart disease risk factors. Journal of Occupational Medicine 23:551-5.

Day, A.L., \& Jreige, S. (2002) Examining Type A behavior Pattern to explain the relationship between job stressors and psychosocial outcomes. Journal of Occupational Health Psychology, 7, 109-120.

Derogatis, L.R., Lipman, R.S., Rickels, K., Uhlenhuth, E.H. and Covi, L., (1979) The Hopkins Sympton Checklist (HSCL): A Self-Report Symptom Inventory, Behavioural Sciences, 19, 1-15.

Edwards, J.R., Baglioni, A.J. \& Cooper, C.L. (1990) Examining the relationships among self-report measures of the Type $A$ Behavior Pattern: The effects of dimensionality, measurement error, and differences in underlying constructs. Journal of Applied Psychology. $75,440-445$.

French-Belgian Collaborative Group (1982) Ischemic heart disease and psychosocial patterns: prevalence and incidence studies in Belgium and France, Advanced Cardiology, 29:25-31.

Friedman, H.S. \& Booth Kewley, S. (1987) Personality, Type A behavior, and coronary heart disease: The role of emotional expression. Journal of Personal Social Psychology, 53, 783-792.

Friedman, M., \& Rosenman, R.H. (1974) Type A behavior and your heart. London: wildwood House.

Hagihara, A., Tarumi, K., \& Morimoto, K., (1998) Type $A$ and type $B$ behaviors and facts related to job sastisfaction among male white-collar workers. Environmental Health Preventative Medicine 2:139-44.

Hallberg, V.E., \& Johansson, G. \& Schaufeli, W.B.(2006) Individual behavior patterns, burnout and work engagement. Unpublished manuscript. Department of Psychology, Stockholm University.

Hansson, R., \& Hogan, R. \& Johnson, J.A. (1983) Disentangling Type A Behavior: The roles of ambition insensitivity and anxiety. Journal of Research on Personality, 17, 186-197.

Haynes, S.G., Feinleib, M., \& Kannel, W.B. (1980) The relationship of psychosocial factors to coronary heart disease in teh Framingham 
study: Eight year incidence of coronary heart disease. American Journal of Epidemiology, 111:37-58.

Haynes, S.G., Levine, S., Scotch, N., Feinleib, M., \& Kannel, W.B. (1978). The relationship of psychosocial factors to coronary heart disease in the Framingham study. I: Methods and risk factors. American Journal of Epidemiology, 107, 362-382.

Helmreich, R.L. Spence, J.T. \& Pred, R.S. (1988) Making it without losing it: Type $A$, achievement motivation and scientific attainment revisited. Personality and Social Psychology bulletin, 14, 495-504.

Ivancevich, J.M., \& Matteson, M.T. (1988) Type A behavior and the healthy individual. British Journal of Medical Psychology, 61, 37-56.

Iwata, N., Suzuki, K, Saito, K., \& Abe, K., (1992) Type A personality, work stress and psychosocial distress in Japanese adult employees. Stress Medicine 8:11-21.

Jenkins, C.D., Zysanski, S.J. \& Rosenman, R.H., (1979) The Jenkins Activity Survey. New York: Psychological Corp.

Kayaba, K., Yazawa, Y., Natsume, T., Yaginuma, T., Hosaka, T., Hosoda, S., \& Tanada, T., (1990) The relevant of psychosocial factors in acute ischemic Herat disease: a case-control study of a Japanese population. Japanese Circulation Journal 54:464-71.

Kivimaki, M., Kalimo, R., \& Julkinen, J. (1996) Components of Type A behavior pattern and occupational stressor-strain relationship: Testing different models in a sample of industrial managers. Behavioral Medicine, 22, 67-76.

Matthews, K.A. (1982) Psychological perspectives on the Type A behavior pattern. Psychological Bulletin, 91, 293-323.

Matthews, K.A., \& Haynes, S.G. (1986) Type A behavior pattern and coronary disease risk: Update and critical evaluation. Am J. Epidemiol 123:923960.

Pickering, T.G., (1985) Should studies of patients undergoing coronary angiography be used to evaluate the role of behavioral risk factors for coronary heart disease? Journal of Behavioral Medicine, 8:203-13.

Pred, R.S., Helmreich, R.L., \& Spence, J.T. (1987) The development of new scales for the Jenkins Activity Survey measure of the TABP construct. Social and Behavioral Science Documents, 16, 51-52. 
Quinn, R.P. and Shepard, L.J., (1974) The 1972-73 Quality of Employment Survey, Ann Arbor, MI. Institute for Social Research, University of Michigan.

Rosenman, R.H., (1985) Health consequences of anger and implications for treatment. In M.A. Chesney \& R.H. Rosenman (eds) Anger and hostility in cardiovascular and behavioral disorders. New York: Hemisphere/McGraw-Hill pp. 131-140.

Rosenman, R.H., Brand, R.J., Sholts, R.I., \& Friedman, M., (1976) Multivariate prediction of coronary heart disease during 8.5 year follow-up in the Western Collaborative Group Study. American Journal of Cardiology 37:903-10.

Rosenman, R.H., Friedman, M., Straus, R., et al. (1964) A predictive study of coronary heart disease: the Western Collaborative Group Study. JAMA, 15-22.

Rosenman, R.J., Brand, J.H., Jenkins, C.D., Friedman, M., Straus, R. \& Wurm, M., (1975) Coronary heart disease in the Western Collaborative Group Study: final follow-up experience of 8.5 years. JAMA, 233: 872-7.

Schnall, P.L., \& Landsbergis, (1994) P.A., Job strain and cardiovascular disease. Annual Review of Public Health, 15:381-411.

Shekelle R.B., Gale, M. \& Norusis, M. (1985) Type A score (JAS) and risk of recurrent coronary heart disease in the Aspirin Myocardial Infarction Study. American Journal of Cardiology, 56, 221-5.

Shekelle, R.B., Holley, S.B., Neaton, J.D. et al. (1985) The MRFIT behavior pattern study. Type A behavior and incidence of coronary heart disease. American Journal of Epidemiology, 122: 559-70.

Siegman, A.W., \& Smith, T.W. (1994) Anger, hostility and the heart. Hillsdale, NJ: Lawrence Erlbaum.

Spence, J.T., Helmreich, R.L., \& Pred, R.S. (1987) Impatience versus achievement strivings in the Type A pattern: Differential effects on students' health and academic achievement. Journal of Applied Psychology, 72, 522-528.

Spence, J.T., Pred, R.S.., \& Helmreich, R.L. (1989) Achievement strivings, scholastic aptitude and academic performance: A follow-up to "Impatience versus achievement strivings in the Type A pattern. Journal of Applied Psychology, 74, 176-178. 
Williams, R.B., Haney, T.L., Lee, K.L., Long, Y., Blumenthal, J.A., Whalen, R.E., (1980) Type A behavior, hostility and coronary atherosclerosis. Psychosomatic medicine 42:539-49.

Yoshimasu, K. (2001) Relation of Type A Behavior Pattern and job-related psychosocial factors to non-fatal myocardial infarction: A case-costed study of Japanese male workers and women. Psychosomatic Medicine, 63, 797-804. 